\title{
Design and Construction Criteria of Twin Tunnel: Taking an Adverse Wind Condition Effects on Air Pollution Short Circuit at Tunnel Portals as a case
}

\author{
Miloua $\mathrm{H}$ \\ Department of Mechanical engineering, Laboratory of structures Mechanics and Solids LMSS, Faculty \\ Technology, University Djillali Liabes Sidi Bel Abbes 22000 Algeria, phone:+213772397141. Orcid.org/0000- \\ 0003-1845-5591 \\ Corresponding Author: miloua_hadj@yahoo.fr
}

Received: 14-10-2019

Accepted: 07-01-2020

\begin{abstract}
This paper aims to study the influence of the tunnel portal designs, wind conditions and ventilation rate on the amount of air pollution short circuit from one tunnel tube to the other. These effects are investigated by Computational Fluid Dynamics (CFD) code used a Large Eddy Simulation (LES) method to control air quality inside the tunnel and reduced as far as possible a short circuited (flow Recirculation) flow level. A validation of CFD code to experimental data in 1:100 scale model of the road traffic tunnel tested in windtunnel showed that the CFD gave satisfactory prediction of the air pollution short circuit in the vicinity of tunnel portal. The predicted concentration of the gas tracer $\left(\mathrm{CO}_{2}\right)$ used as the safety criterion provide the useful information about a short circuit amount resulted for each structural variant of tunnel portals, such as a central dividing wall built as extensions from the end of road tunnel and offset tunnel portal entrance exit tested under different speed ratio $U_{w} / V_{t}$ of wind and ventilation. A detailed look at results is beyond the scope of analysis to determine optimal air pollution short circuit percentages. Finally, the perfect tunnel portals geometry can be suggested.
\end{abstract}

Key words: Air Pollution, Tunnel Portals, Wind, Ventilation, CFD.

\section{Introduction}

Ventilation and fire safety design in road tunnels under external wind effect are one of the most complexes issues that need to be carefully considered and analyzed in the designing stage of any tunnel project. Road tunnels create an enclosed space around vehicles where emissions from the vehicles can build up to unacceptable levels without an engineered ventilation system which can be required for dilution emissions by providing fresh air and then removing the exhaust air from the tunnel. Most of the road tunnels were designed as a twin tube equipped with longitudinal ventilation system in each traffic direction. The disadvantage of this system of ventilation reported by Kashef et al. (2003) is that adverse wind conditions maybe short-circuit the flow from the exhaust tube to the nearby tube, causing the contamination of fresh in supply tube. Two portals designs can be used to reduce greatly a flow recirculation: an offset head of one tube relative to another "Offset Tunnel Portal Entrance Exit", or more simply, to use a "Central Dividing Wall" at sufficient height built as extensions from the ends of tunnels beyond by staggering the portals longitudinally.

Futoshi Tanaka et al. (2016) investigated the interaction between exhaust jet and wind using a 1:12 scale model tunnel was conducted to evaluate effects of a transverse external wind on the performance of roof openings in fire tunnel. Muhič and Mazej (2014) clearly indicated the negative effect of external wind in the case of a longitudinally ventilated road tunnel. Two different models for the dispersion of tunnel exhausts are developed by Oettl et al (2013) to simulate the dispersion of pollutants in the vicinity of road tunnel portals. A testing ventilation system of close tunnel model was established by Tan et al. (2015) is intended to provide drivers 
and passengers with an adequate supply of oxygen and to dilute toxic gases emitted from vehicles to safe concentrations, ventilation systems, such as jet fans and exhaust shafts. A full scale fire tunnel has been presented by Yousaf et al. (2014) divided a recirculation to three subphenomenon: the emission, the transmission and the nuisance caused by the smoke. Gehrig et al. (2013) study the relation between the smoke source and the tunnel users. The remaining threats to tunnel users are the loss of visibility and of possible intoxication.

There are some experimental works (Baumann, 1979; Chock, 1982) which considers as the earliest on flow recirculation issues involved laboratory scale testing the impact of polluted tunnel exhausts in urban area. The most notable work that done by Koopmans (2005) was determinate the amount of air pollution short circuit in a scale-model (1:150) of the tunnel tested with structural variants for the tunnel portals and wind conditions. The technical, architectural and landscape aspects of tunnel portal design are analyzed by Peila and Pelizza (2002) they provide a systematic comparison of different architectural solutions to force designers to better integrate infrastructure with the environment. Brousse et al. (2005) have studied the impact of the background pollution and evaluation of the tunnel exhausts on air quality. Yang et al. (2012) study the effect of structural factors on waste gas cross flowing around portal of highway tunnels. There are results obtained by measurements on Aeraulic mock-ups (Gourdol, 2004). These measurements were made in wind tunnel involved a detailed description of the tests. The measurement were made for a tunnel (or cut-and-cover tunnel) opening into a cutting.

An Experimental investigation in a wind tunnel described by Mirzai et al. (1994) provided some data about the influence of the wind direction of on flow and dispersion of pollutants around small building. Also, Nadel et al. (2003) use of wind tunnel testing to develop air rights structures over tunnel exit portals. Lim and Ohba (2015) studies through wind tunnel experiments and a detached eddy simulation a wind flows by variations of direction around rectangular prisms with different sizes. A series of wind-tunnel tests the vertical variation of wind directions were investigates (Weerasuriya et al., 2016; Li et al., 2016) (i.e., the so-called 'twist effect'). LES (Large Eddy Simulation) has been successfully applied to some several airflows related to buildings (Davidson and Nielsen, 1996; Murakami, 1998; Dagnew and Bitsuamlak, 2013) reviews the up to date state of the art in the numerical evaluation of wind loads on buildings. Important aspects of numerical modeling including a turbulence modeling, inflow boundary conditions, ground surface roughness, near wall treatments, and quantification of wind loads using the techniques of computational fluid dynamics (CFD) were summarized. Relative advantages of Large Eddy Simulation (LES) over Reynolds Averaged Navier-Stokes (RANS) and hybrid RANS-LES over LES were discussed. Overall LES based simulations seem suitable for wind load evaluation in tall building by computing large vortices as distinct flow fields and Small vortices within the size of the mesh are modeled in terms of the local mean mesh model (Dagnew and Bitsuamlak, 2014). An admirable paper of Lipecki and Flaga (2013) presents theoretical background for a semi-empirical, mathematical model of critical vortex excitation of slender structures of compact cross-sections, demonstrate mathematical background of the vortex excitation model for a theoretical case of the structure section and extrapolate a mathematical model for the application to real structures.

A tunnel bi-tube, where each of the tubes a particular direction of the traffic circulation, a problem of flow recirculation can occur at the two head of tunnel. Indeed, as shows Fig.1, if we take place in one of the heads, the forced ventilation imposes for one of the two tubes a polluted debit of air outlet, while in the nearby tube; it imposes a fresh air inlet. So, it is clear that in the absence of particular precautions, such a configuration can impose to short circuit of the polluted air in the tube with fresh air. If these techniques can be considered a contribution in this field, we can nevertheless regret that no (in any case to our knowledge) results of studies allowing quantifying the efficiency of the device according to its geometrical characteristics (size of the central dividing wall, offset length, etc.). The main objective is to provide and answer to 
the diverse questioning related to this problem and their resolution by two methods: Central dividing wall used offset tunnel portal entrance exit: what length is it necessary to offsetting head? What should be the dimensions of the central dividing wall to prevent a short circuit effect? Are there any critical dimensions or optimal dimensions and wind conditions for different constructional scenarios? Series of tests based on a parametric approach is carried out on a reduced scale model.

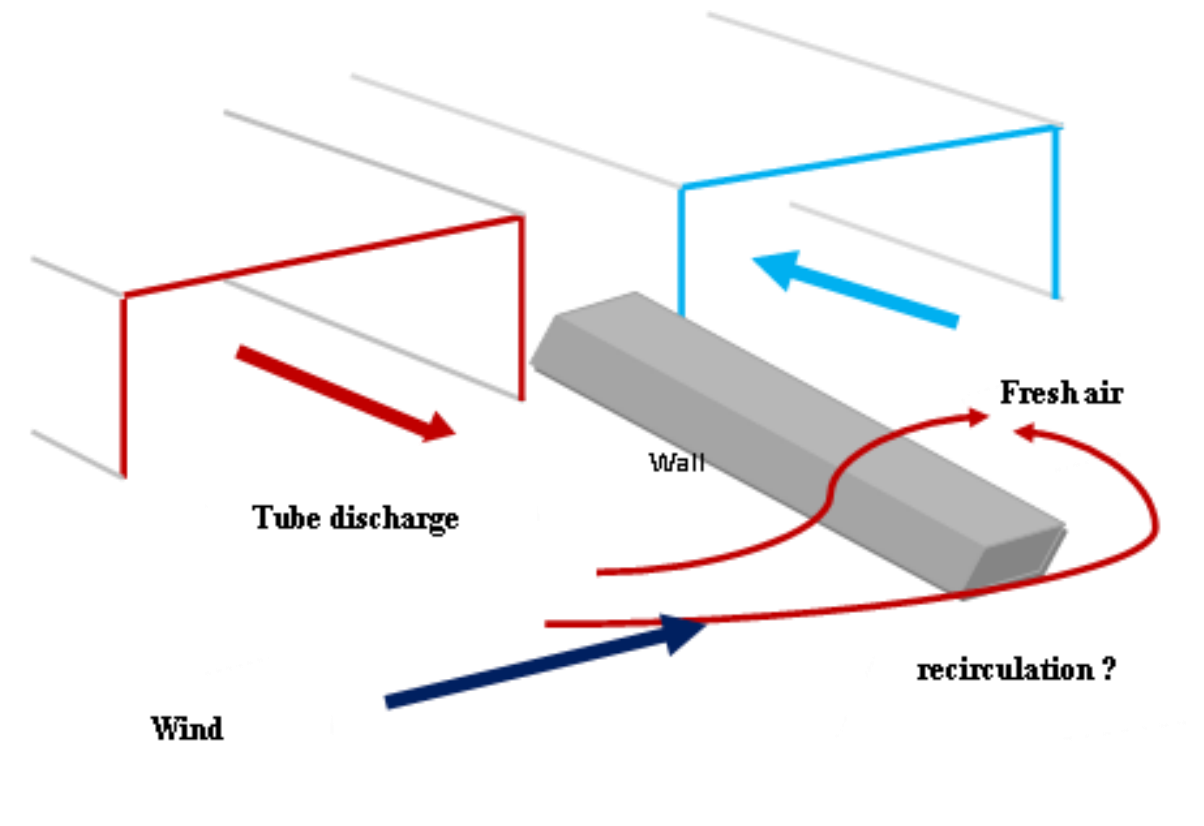

Fig. 1. Air pollution short circuit in the vicinity of tunnel portal.

This paper is divided into three major sections. Section 1 is devoted to a detail discussion about CFD code used named Fire Dynamics Simulator (FDS) and a numerical sensitivity of a computational mesh is conducted to get the best degree of grid refinement. The second section describes the previous experimental strategy used during a comparison and validation of obtained numerical results. In section 3 a physical analysis followed through the expected code to offer more understanding about obtainable results. Finally, some general issues related to the role of modeling to support sustainable tunnel design are discussed.

\section{Materials ad methods}

\subsection{Calculation Tool and Computational Domain}

\section{a. Domain size}

The calculation domain is $60 * 60 * 60 \mathrm{~cm}^{3}$ in the $\mathrm{X} \mathrm{Y}$ and $\mathrm{Z}$ directions respectively (Figure 2). The regular Eulerian grid contains $300 * 300 * 300$ grid cells, which gives a cell size of $0.2 \mathrm{~cm}$ in each direction. This cell size has been chosen after testing that results are insensitive to a further refinement of the mesh $(1 \mathrm{~cm} ; 0.2 \mathrm{~cm})$, the actual grid is appropriate which is belonged to the small geometry taken such as central dividing wall thickness of $1 \mathrm{~cm}(1 \mathrm{~m}$ real) at 1:100 reduced scale tunnel(See Fig.2).

\section{b. Boundary and initial conditions}

The portals of two tubes (see Fig.2.a) and their surrounding sited in the computational domain of $60 \times 60 \times 60 \mathrm{~cm}^{3}$ to avoid any numerical influence of boundary conditions. The boundary condition for the three sides of the domain $(\mathrm{X}=\mathrm{X} \max , \mathrm{Y}=\mathrm{Y}$ max, $\mathrm{Z}=\mathrm{Z}$ max) respectively taken passive opening: ambient temperature, ambient pressure and zero velocity gradients. This set 
up has been chosen in order to stick as much as possible to experimental condition used by Vauquelin and Lesueur (1998). About a side (X=0) which involved inlet and outlet sections of discharge and nearby tubes, a constant speeds values $(\mathrm{m} / \mathrm{s})$ are set in inlet and outlet sections of discharge and nearby tubes respectively(in opposed direction) for simulating the extractor and supply fans. In the right side of exhaust tube $Y=Y$ min of computational domain, an entrance wind velocity is fixed to simulate a wind effect.

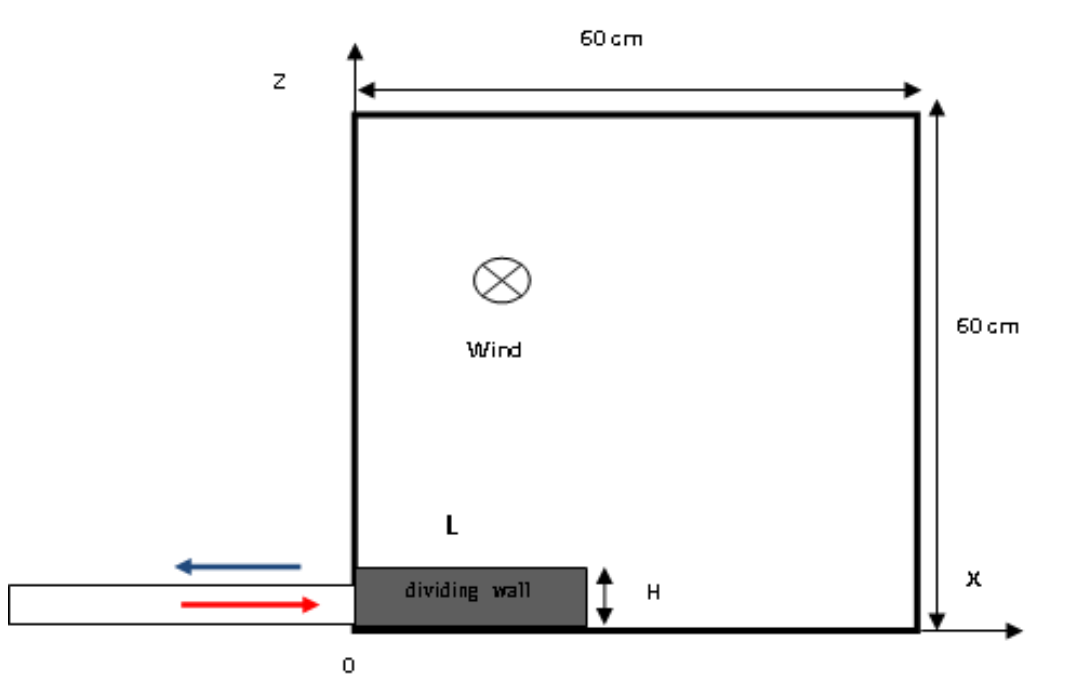

(a)

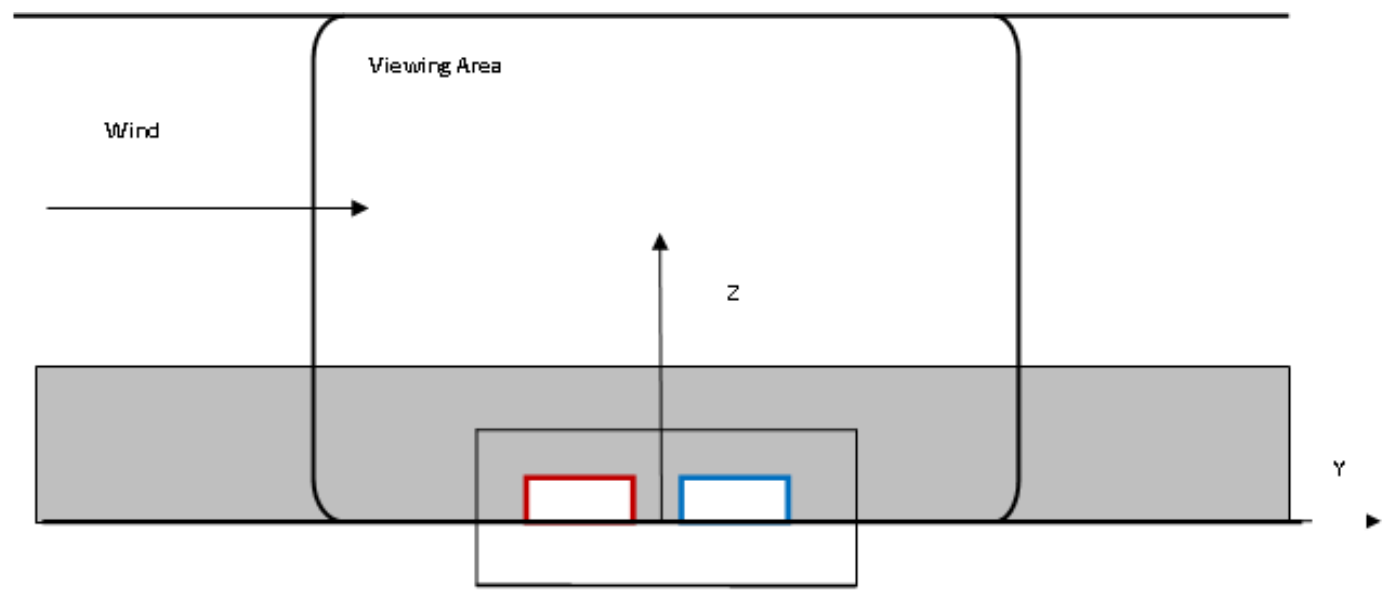

(b)

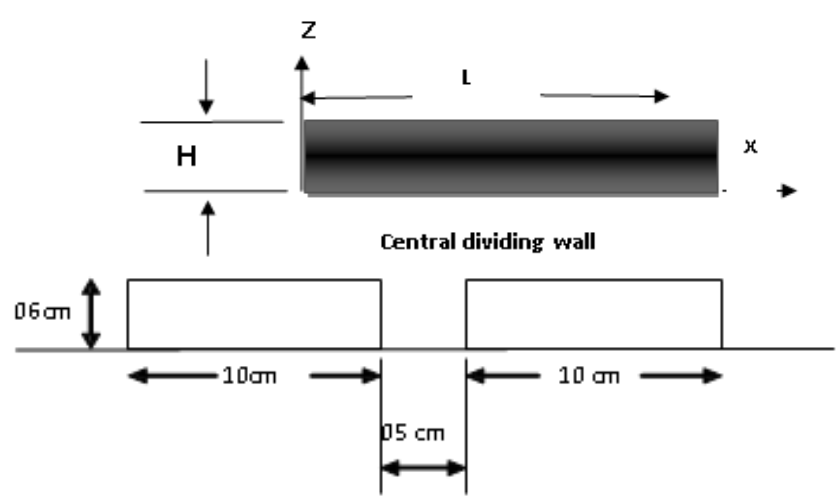

(c)

Fig. 2. Representation of the calculation domain used by CFD and experiment in order of 1:100. 
In order to observe the effect of dimensionless ratio $m=U_{w} / V_{t}$ where $U_{w}$ is the wind speed and $V_{t}$, the flow velocities in the exit tube (discharge) and entry tube (nearby) $V_{\mathrm{t} 1}=\mathrm{V}_{\mathrm{t} 2}=V_{t}$ of 10 m.s. 5 m.s. ${ }^{-1}$ and 2.5 m.s $\mathrm{s}^{-1}$ respectively(see Fig.2.b\&c). The flow boundary condition for the wind speed $U_{w}$ is $5 \mathrm{~m} / \mathrm{s}$ and fixed direction for all tests. The tunnel portal and ground materials are assumed to be perfectly insulated, an adiabatic boundary condition is imposed at the surface, as follows,

$$
K_{S} \frac{\partial T_{S}}{\partial x}(0, t)=0
$$

At the start of calculation, the temperature is ambient, and the flow velocity is zero everywhere. The initial time step is set automatically by dividing the size of a mesh cell by the characteristic velocity of the flow. The default value of time step is $5\left(\delta_{X} \delta_{Y} \delta_{Z}\right)^{\frac{1}{3}} / \sqrt{g H}$ s, where $\delta_{X}, \delta_{Y}, \delta_{Z}$ are the dimensions of the smallest mesh cell, $H$ is the height of the computational domain, and $g$ is the acceleration of gravity $g=9.81 \mathrm{~m} . \mathrm{s}-1$. During the calculation, the time step is adjusted so that the CFL (Courant, Friedrichs, Lewy) condition is satisfied. Every time step, the CFL number is computed in each mesh cell, and the time step, $\partial t$, is adjusted if the maximum value of the CFL number is not between CFL_MIN and CFL_MAX, whose default values are 0.8 and 1.0, respectively. Note that by default the time step is never allowed to increase above its initial value. Resetting the stability parameters is not recommended except in very special circumstances, as they can lead to simulations failing due to numerical instabilities.

\section{c. CFD Model}

With the advent of more powerful computers, the Computational Fluid Dynamics (CFD) modeling technique is rapidly expanding. Fire Dynamics Simulator (FDS) (McGrattan et al., 2013) is a CFD model of fire-driven fluid flow. The software solves numerically a form of the Navier-Stokes equations appropriate for low-speed (low Mach number), thermally-driven (buoyant) flow with an emphasis on smoke and heat transport from fires. This CFD is open source and freely available provided by the National Institute of Standards and Technology (NIST) of the United States Department of Commerce. The formulation of the equations and the numerical algorithm are presented in the Fire Dynamics Simulator Technical Reference Guide (McGrattan et al., 2013). FDS consists of two computer programs, the first called simply FDS, under a FORTRAN 90. The used version of computer program is FDS 6.0 (McGrattan et al., 2013). The second, called Smokeview is an OpenGL graphics program that allows one to visualize the results. All the input parameters required by FDS to describe the particular scenario of interest are conveyed via one or two text files created by the user. FDS requires a relatively fast CPU and a substantial amount of random-access memory (RAM). Computer system used characterized by Processor Intel ® core (TM) i7 4790@3.6 GHz memory RAM 16.0 Go.

\section{d. Sub-Grid Model}

The basic idea of Large Eddy Simulation (LES) demonstrated by Rehm and Baum (1978) is to resolve the largest turbulent motions and to filter out the small-scale motions. This is achieved by spatial filtering of the governing equations. A full flow field, $\Phi(\vec{x}, t)$, is decomposed into a resolved component, $\bar{\Phi}(\vec{x}, t)$, and a subgrid-scale (SGS)component, $\Phi^{\prime}(\vec{x}, t)$, i.e., $\Phi(\vec{x}, t)=\bar{\Phi}(\vec{x}, t)+\Phi^{\prime}(\vec{x}, t)$. The resolvable component, $\bar{\Phi}(\vec{x}, t)$, is obtained from the filtering operation by taking a function $G\left(\vec{x}-\vec{x}^{\prime}, \Delta\right)$ as the filter kernel:

$$
\bar{\Phi}(\vec{x}, t)=\int_{\Omega}\left(\vec{x}-\vec{x}^{\prime}, \Delta\right) \Phi(\vec{x}, t) d \vec{x}^{\prime}
$$


Where $\Delta$ is the filter width related to the local mesh configuration by $\Delta=\left(\delta_{X} \delta_{Y} \delta_{Z}\right)^{\frac{1}{3}}$ with $\delta_{X}$, $\delta_{Y}$ and $\delta_{Z}$ the sizes of a grid cell. Eddies of a size larger than $\Delta$ are resolved, smaller eddies are filtered out of the governing equations. This means that the resolved values are computed on a numerical grid, while the unresolved field has to be modelled.

Applying the filtering operation to each term in the conservation equations of mass, momentum, energy and species, and decomposing the dependent variables $(u, v, w, P$,etc.) into resolved (the large-scale eddies) and subgrid components (the smallest eddies ) results in the filtered governing equations, shown below:

$$
\begin{aligned}
& \frac{\partial \rho}{\partial t}+\frac{\partial \rho \bar{u}_{j}}{\partial x_{j}}=0 \\
& \frac{\partial \rho \bar{u}_{i}}{\partial t}+\frac{\partial\left(\rho \bar{u}_{i} \bar{u}_{j}\right)}{\partial x_{j}}+\frac{\partial \bar{P}}{\partial x_{i}}-\rho g_{i}=\nabla \cdot \bar{\tau}_{i j, S G S}
\end{aligned}
$$

Where the bar above the various quantities denotes the filtered variable. The unresolved field, $\Phi^{\prime}(\vec{x}, t)$, is modeled by the Smagorinsky (1963) in which the SGS Reynolds stress tensors, $\bar{\tau}_{i j, S G S}$ ,are related to the local large-scale rate of strain $\bar{\tau}_{i j, S G S}=2 u_{t} \bar{S}_{i j}$ and $\bar{S}_{i j}=\frac{1}{2}\left(\frac{\partial \bar{u}_{i}}{\partial x_{j}}+\frac{\partial \bar{u}_{j}}{\partial x_{i}}\right)$. Following the analysis of Smagorinsky (1963), the eddy viscosity can be modelled as $\mu_{t}=\rho\left(C_{S} \Delta\right)^{2}\left|\bar{S}_{i j}\right|$. Here, $\left|\bar{S}_{i j}\right|$ is the magnitude of the large-scale strain rate tensor, $\bar{S}_{i j}$, and $C_{S}$ the Smagorinsky constant, lying between 0.1 and 0.21 , is set as low as possible to reduce numerical diffusion, taken as 0.1 in this paper. The turbulent heat flux is based on an eddy viscosity assumption, resulting in the following energy equation:

$$
\frac{\partial \rho \bar{h}}{\partial t}+\frac{\partial\left(\rho \bar{u}_{i} \bar{h}\right)}{\partial x_{j}}-\frac{\partial}{\partial x_{j}}\left(\frac{\mu_{t}}{\operatorname{Pr}_{t}} \frac{\partial \bar{h}}{\partial x_{j}}\right)=\dot{q}_{C}^{\prime \prime \prime}-\nabla \cdot q_{r}
$$

We solve in such flows case without any heat addition, the flow is assumed incompressible with a low speed flow. This approximation indicates density is not a function of pressure and temperature. The $\mathrm{CO}_{2}$ gas was used as a tracer. The tracer, which exhausted $\mathrm{CO}_{2}$ at some fixed rates, was installed in the cross section of discharge tube.

A perfect gas equation:

$$
\mathrm{P}_{0}(\mathrm{t})=\sum_{\mathrm{i}=0}^{\mathrm{n}} \frac{\mathrm{Y}_{\mathrm{i}}}{\mathrm{M}_{\mathrm{i}}}=\frac{\Re \rho \mathrm{T}}{\mathrm{M}}
$$

with :

- $\Re$ la constant of perfect gas,

- $\quad \mathrm{M}_{\mathrm{i}}$ molar mass of species i $\left(\mathrm{CO}_{2}\right.$ and fresh air $)$

Where $\operatorname{Pr}_{t}$ denotes the turbulent Prandtl number varying from 0.2 to 0.9 , and is taken as 0.5 in this work, even though there were no significant changes by using different values in the test data near central dividing wall. The energy equation without fire (inert flow): exclude the rate of heat release per unit volume, $\dot{q}_{C}^{\prime \prime}$, and the radiant energy flux, $\nabla . q_{r}$ : 


$$
\frac{\partial \rho \bar{h}}{\partial t}+\frac{\partial\left(\rho \bar{u}_{i} \bar{h}\right)}{\partial x_{j}}-\frac{\partial}{\partial x_{j}}\left(\frac{\mu_{t}}{\operatorname{Pr}_{t}} \frac{\partial \bar{h}}{\partial x_{j}}\right)=0
$$

\section{e. Method of Resolution}

The finite-difference technique is used to discretize the partial differential equations. This procedure entails the subdividing of the calculation domain into a finite number of cells. The velocities (ui) are taken on the boundary of each cell; and all the scalar variables are taken at cell centres. This staggered grid leads to a very efficient differencing scheme for the equations. All spatial derivatives are approximated by second-order central differences and the flow variables are updated using an explicit second-order Runge-Kutta scheme.

The grid size declared above is the most important numerical parameter in the model, as it dictates the spatial and temporal accuracy of the discretized partial differential equations. The calculations were performed using coherent computational mesh based to the best degree of grid refinement can consider that is particularly adequate and done good convergence with experimental data and required during Analysis to observe a small vortex and flow movement near Wall (See Fig.3). A numerical techniques used to solve the governing equations within a model can be a source of error in the predicted results. The error depends upon the length of the time step $\Delta t$. If this time step is deemed to be too long to introduce severe uncertainties due to the assumptions, the length of forward stepping of the front is decreased resulting in a shorter time step. All the results from the computer output were time-averaged from $20 \mathrm{~s}$ to 2 min chose before a several runs tests with different forward length steps have been performed to ensure convergence. Musser et al. (2001) investigated the use of FDS for course grid modeling of nonfire and fire scenarios. The results of her study indicate that non-fire simulations can be completed more quickly than fire simulations because the time step is not limited by the large flow speeds in a fire plume.

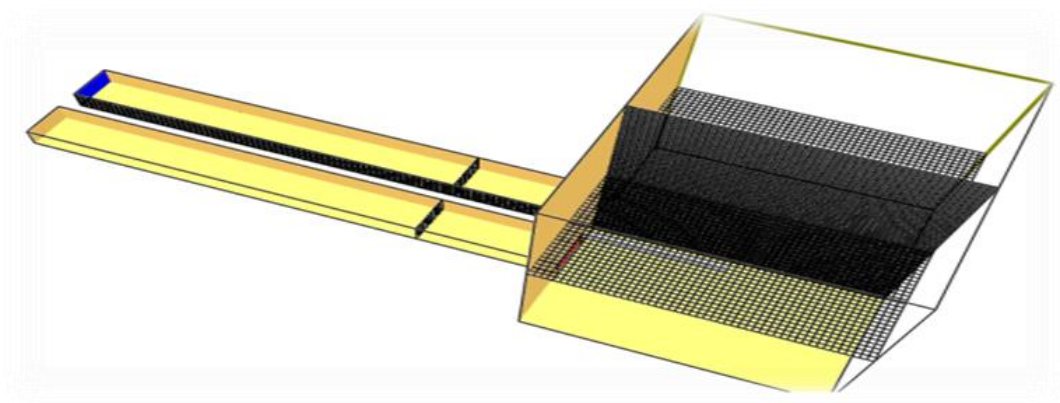

(a)

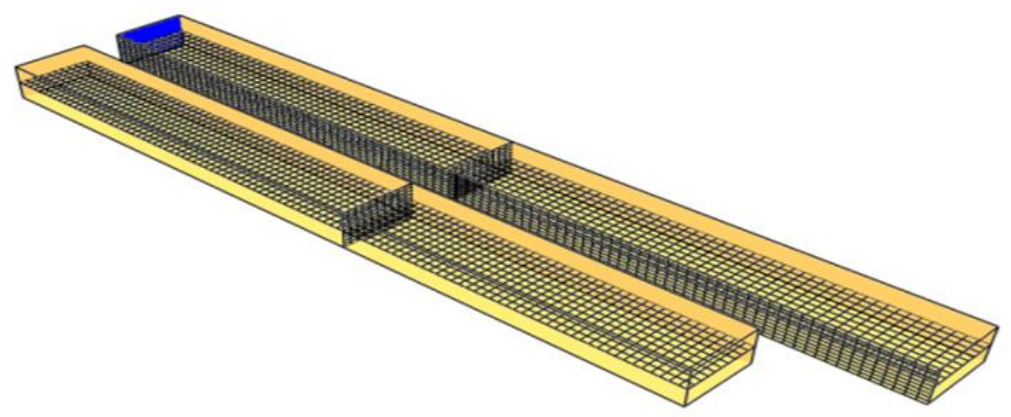

(b)

Fig. 3. Meshed model using a coherent numerical grid:(a) mesh grid of central dividing wall and (b) mesh grid of offset tunnel portal entrance exit 


\subsection{Outline of the Experiment}

A series of experiments conducted by Vauquelin and Lesueur (1998) with mock-up of a 1:100 placed in the subsonic wind tunnel with closed vein, as shown in Fig.2, which is assumed to be a part of a tunnel underground. built by two tubes of rectangular cross-section arranged parallel at plane where the wind directed perpendicular (this angle is reported to causing maximum recirculation rate) to the axis of both tubes of tunnel in the direction from the exhausted (discharge) tube to supply tube and tunnel portals vicinity area (width $=60 \mathrm{~cm}$, depth $=60 \mathrm{~cm}$, height $=60 \mathrm{~cm}$ ) were lined with an insulation board. Two identical openings are: discharge tube and nearby tube (height $=10.0 \mathrm{~cm}$, width $=6 \mathrm{~cm}$ ) were employed in the experiments. Two fans (in an exhaust and supply tubes) are adjusted by adaptation the pressure loss . A cross-wind was supplied from the rectangular duct, whose dimension was $60 \mathrm{~cm} \times 60 \mathrm{~cm}$, which is connected to the fan via a honeycomb filter. The values of cross-wind mean the average velocities and these were obtained by dividing the total volumetric flow by the effective area. The wall was placed in such a way that its short side faced the cross-winds. Its thickness is fixed at $1 \mathrm{~cm}\left(1 \mathrm{~m}\right.$ real). In all the experiments described in the following, the $\mathrm{CO}_{2}$ gas was used as a tracer. The tracer, which exhausted $\mathrm{CO}_{2}$ at some fixed rates, was installed in the cross section of discharge tube. Gas $\mathrm{CO}_{2}$ is adopted, because it is easy to control the exhaust flow rate. In practice, the fan alimented the exhausted tube were used to pump a mixture of air and $\mathrm{CO}_{2}$. Note that it was not working with a pure carbon dioxide, initially for reasons of economy, but also and especially to minimize the effects of differences density that have no place to exist for these tests. Finally, be noted that the mixture of air $+\mathrm{CO}_{2}$ (which represents the stale of air in the exhausted tube) is characterized by passive smoke to carry out systematic visualizations.

All tests in the experiment and CFD are carried out in the case where $V_{t 1}=V_{t 2}=V_{t}$. The wind speed and wind direction were kept constants $U_{\mathrm{w}}=5 \mathrm{~m} . \mathrm{s}-1$ blowing at about $90^{\circ}$ to the tunnel axis(speed of wind tunnel). The speed $V_{t}$ in both tubes is adjusted as to cover three values of the parameter of jet: $\mathrm{m}=\mathrm{U}_{\mathrm{w}} / \mathrm{V}_{\mathrm{t}}=0.5$ (equal to the half of wind velocity), $\mathrm{m}=1.0$ (equal to the wind velocity) and $\mathrm{m}=2.0$ (equal to the double of wind). Two sets of tests, TEST I, II, were conducted were carried out for examining the effect of the cross-winds for short circuit flow. The amounts of short circuit flow (recirculation rate) were calculated under variant portal designs such as "Central dividing wall", "Offset Tunnel Portal Entrance Exit" and variant speed ratio $\mathrm{m}=$ $\mathrm{U}_{\mathrm{w}} / \mathrm{V}_{\mathrm{t}}$ where $\mathrm{U}_{\mathrm{w}}$ is the wind speed and $\mathrm{V}_{\mathrm{t}}$ the flow velocity in the neighboring tube $\left(\mathrm{V}_{\mathrm{t} 1}\right.$ and $\left.\mathrm{V}_{\mathrm{t} 2}\right)$. In the test I of "Central dividing wall", each value of speed ratio $m=U_{w} / V_{t}$ systematically testing three values of the height $\mathrm{H}(\mathrm{cm})$ of central dividing wall $\mathrm{H}=4 \mathrm{~cm}(4 \mathrm{~m}$ real $), \mathrm{H}=06 \mathrm{~cm}(6$ $\mathrm{m}$ real) and $\mathrm{H}=8 \mathrm{~cm}(8 \mathrm{~m}$ real). Also, in each value of $\mathrm{H}$ testing five values of wall length $\mathrm{L}(\mathrm{cm})$ : $\mathrm{L}=05 \mathrm{~cm}(5 \mathrm{~m}$ real $), \mathrm{L}=10 \mathrm{~cm},(10 \mathrm{~m}$ real $), \mathrm{L}=15 \mathrm{~cm},(15 \mathrm{~m}$ real $), \mathrm{L}=20 \mathrm{~cm}(20 \mathrm{~m}$ real $)$ and $\mathrm{L}$ $=25 \mathrm{~cm}(25 \mathrm{~m}$ real). In the test II, a range of $\Delta \mathrm{L}(\mathrm{cm})$ offsetting head "Offset Tunnel Portal Entrance Exit" (see Fig.3) from 5 to $25 \mathrm{~cm}$ (5 to $25 \mathrm{~m}$ real) were tested. For each configuration, $\mathrm{CO}_{2}$ concentrations are measured in both tubes it can be better to measure $\mathrm{CO}_{2}$ (carbon dioxide) instead of every toxic component that is always the most predominant product of combustion, and is, therefore, a good standard of the total amount of accumulated exhausts and thereby the necessary ventilation.

A diffusion process is governed by the turbulence, thus directly related to the value of the Reynolds number. Unfortunately, such reduced scale; the conservation of Reynolds number can't be realized. Consequently, it was proposed to use hydrodynamic similitude called limited, i.e. maintain on model a Reynolds numbers sufficiently high to ensure turbulent flow character, with reference to further comprehension about the flow with high Reynolds number turbulence and FSI fluid-solid interaction Musser et al. (2001). Very low speeds were avoided to maintaining a Reynolds number upper than the critical value of 5000 . The measures to be carried out for this series of tests are: The velocity in the supply and the exhausted tubes, the wind speed (under the wind tunnel) and $\mathrm{CO}_{2}$ concentration the discharge tube and nearby tube . Air flow velocity in the duct was measured by a Pitot velocity probe associated with Flow-meters 
of floating ball. Pitot tubes are placed centrally within the supply lines, far enough from the entrance so that the flow is established. In order to estimate the $\mathrm{CO}_{2}$ concentrations, a gassampling tube for measuring was installed near the head of supply and exhaust tubes. The recirculation rate (Yousaf et al., 2014) is a measure for the amount of pollutants that is flowing from the tube's discharge to a nearby inlet tube. It sums up quantitatively the transmission phenomenon, leaving out all the details of the transmission mechanisms. There are several possible definitions. It may be defined as the ratio of the mass flow of a species entering the inlet tube to the mass flow of the same species leaving the pollutants discharge. Another definition (Gehrig et al., 2013) reported to recirculation of smoke in fire tunnel, as the visibility in the inlet tube is best related to a smoke concentration. A convenient definition for the purposes of this paper is the ratio of the concentration of a species in the flow entering the inlet tube to the concentration of the same species leaving the pollutant discharge. Using $\mathrm{CO}_{2}$ as tracer gas for both CFD and experiment their advantage that does not react with the air while transported from one tube to the other. For a given speeds ratio of wind speed and ventilation the efficiency $\varepsilon$ expressed as a percentage level "\%" ranging between $0 \%$ (no recirculation) to $100 \%$ (critical recirculation) is defined by: $\varepsilon=1-C_{i} / C_{e}$. Where $C_{i}\left(\mathrm{Kg} \mathrm{CO}_{2} \cdot \mathrm{Kg}-1\right.$ Mixture) is the $\mathrm{CO}_{2}$ concentration measured in inlet tube and $C_{e}$ (Kg CO $2 . \mathrm{Kg}-1$ Mixture) is the $\mathrm{CO}_{2}$ concentration measured from exhaust tube. Qualitative analysis of flow in the test section exactly near the head is carried out using global visualizations of the mixture (air $+\mathrm{CO}_{2}+$ smoke) rejected by the exhausted tube and possibly taken up by the exhausted tube. Each test is filmed and stored on videotape.

\section{Results and Discussion}

\subsection{Comparison with experimental results}

The data given from the experiments are compared with the predicted results of the CFD model based to the values of efficiency in different sizes of central dividing wall and offset tunnel portal entrance exit. The work covers a three range of wind speed ratio and fixed cross wind.

\section{a. Offset Tunnel Portal Entrance Exit}

In the worst case situations of offset tunnel portal entrance exit with smaller $\Delta \mathrm{L}=5(\mathrm{~m})$ real the rate of air pollution short circuit to the ingoing tunnel portal from the emitted air pollution of the outgoing tunnel portal can reach a $20 \%$, which means that the efficiency up to $80 \%(\varepsilon=0.8)$. With a good tunnel portal design geometry declared by Koopmans (2005) the rate of air pollution short circuit effects can be limited to $10 \%$ or efficiency $\varepsilon=90 \%$.

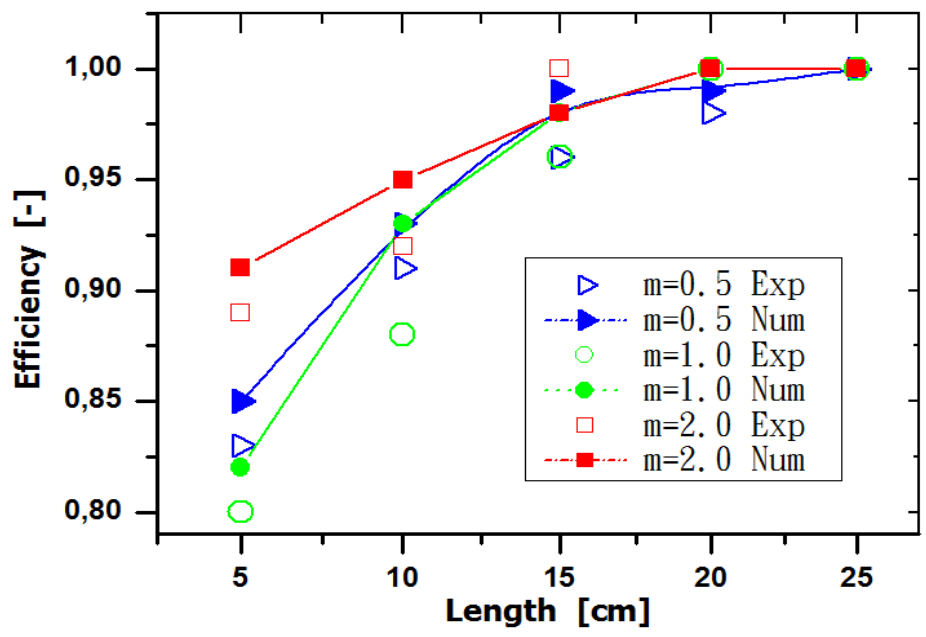

Fig. 4. Efficiency $\varepsilon$ obtained by offset tunnel portal entrance exit method versus the offsetting length $\Delta \mathrm{L}$ under different wind/ventilation conditions $\left(\mathrm{m}=\mathrm{U}_{-} \mathrm{w} / \mathrm{V}_{-} \mathrm{t}\right)=0.5,1$ and 2$)$. 
Figure. 4 indicates that a required offset tunnel portal entrance exit to reach this is between 10 to $15 \mathrm{~m}$ real, up to this value for more than $15 \mathrm{~cm}$ (15 m real) offset head, the recirculation of air pollution process is almost completely eliminated.

\section{b. Central Dividing Wall}

From the measurements and calculations made for the planned road traffic tunnel see Table 1, it appears that the minimum air pollution (aerodynamic) short circuit occurs (high efficiency) registered at a speed ratio of $m=2.0$ The short circuit occurring at the other speeds tested $m=1$ and $\mathrm{m}=0.5$ is generally (considerably) lower. As for the influences of wall height see Table I, we can observe that the height and length of the wall have depending influence on the value of efficiency $\varepsilon$. With length $L \geq 15 \mathrm{~cm}(15 \mathrm{~m}$ real), the efficiency raises (less recirculation) with the height of the wall, which is reasonable. But, for a short wall lower than $L \leq 10 \mathrm{~cm}$ (10 m real), we notice that the efficiency decreases as we increase the height. This phenomenon is explained by the fact that the wall creates inevitably air recirculation zone which can be stronger if the height is important. This zone is able to trap the exhausted air.

Table 1. Efficiency $\varepsilon$ of the central dividing wall under different Wind Speed $U$ with fixed Ventilation V=5 m.s-1 in both tubes

\begin{tabular}{|c|c|c|c|c|c|c|c|c|c|c|}
\hline \multicolumn{11}{|c|}{ Case (a) central dividing wall under speed ratio: $m=U_{w} / V_{t}=0.5$} \\
\hline & \multicolumn{2}{|c|}{$\mathrm{L}=5$} & \multicolumn{2}{|c|}{$\mathrm{L}=10$} & \multicolumn{2}{|c|}{$\mathrm{L}=15$} & \multicolumn{2}{|c|}{$\mathrm{L}=20$} & \multicolumn{2}{|c|}{$\mathrm{L}=25$} \\
\hline \multirow[b]{2}{*}{$\mathrm{H}=4$} & \multicolumn{2}{|c|}{ Exp Num } & \multicolumn{2}{|c|}{ Exp Num } & \multicolumn{2}{|c|}{ Exp Num } & \multicolumn{2}{|c|}{ Exp Num } & \multicolumn{2}{|c|}{ Exp Num } \\
\hline & $0.56 \%$ & $0.58 \%$ & $0.56 \%$ & $0.59 \%$ & $0.56 \%$ & $0.59 \%$ & $0.61 \%$ & $0.63 \%$ & $0.62 \%$ & $0.63 \%$ \\
\hline $\mathrm{H}=6$ & $0.53 \%$ & $0.50 \%$ & $0.53 \%$ & $0.50 \%$ & $0.61 \%$ & $0.68 \%$ & $0.64 \%$ & $0.70 \%$ & $0.68 \%$ & $0.70 \%$ \\
\hline $\mathrm{H}=8$ & $0.53 \%$ & $0.50 \%$ & $0.53 \%$ & $0.50 \%$ & $0.64 \%$ & $0.70 \%$ & $0.71 \%$ & $0.75 \%$ & $0.73 \%$ & $0.76 \%$ \\
\hline \multicolumn{11}{|c|}{ Case (b) central dividing wall under speed ratio: $m=U_{w} / V_{t}=1.0$} \\
\hline & \multicolumn{2}{|c|}{$\mathrm{L}=5$} & \multicolumn{2}{|c|}{$\mathrm{L}=10$} & \multicolumn{2}{|c|}{$\mathrm{L}=15$} & \multicolumn{2}{|c|}{$\mathrm{L}=20$} & \multicolumn{2}{|c|}{$\mathrm{L}=25$} \\
\hline & Exp & Num & Exp & Num & Exp & Num & $\operatorname{Exp}$ & Num & Exp & Num \\
\hline $\mathrm{H}=4$ & $0.58 \%$ & $0.61 \%$ & $0.60 \%$ & $0.63 \%$ & $0.67 \%$ & $0.69 \%$ & $0.68 \%$ & $0.69 \%$ & $0.7 \%$ & $0.72 \%$ \\
\hline $\mathrm{H}=6$ & $0.55 \%$ & $0.52 \%$ & $\%$ & $0.58 \%$ & $0.55 \%$ & $0.70 \%$ & $0.7 \%$ & $0.72 \%$ & $0.70 \%$ & - \\
\hline $\mathrm{H}=8$ & $0.55 \%$ & $0.50 \%$ & $0.56 \%$ & $0.55 \%$ & $0.72 \%$ & $0.73 \%$ & $0.77 \%$ & $0.8 \%$ & $0.78 \%$ & $0.82 \%$ \\
\hline \multicolumn{11}{|c|}{ Case (c) central dividing wall under speed ratio $m=U_{w} / V_{t}=2.0$} \\
\hline & \multicolumn{2}{|c|}{$\mathrm{L}=5$} & \multicolumn{2}{|c|}{$\mathrm{L}=10$} & \multicolumn{2}{|c|}{$\mathrm{L}=15$} & \multicolumn{2}{|c|}{$\mathrm{L}=20$} & \multicolumn{2}{|c|}{$\mathrm{L}=25$} \\
\hline & Exp & Num & Exp & Num & Exp & Num & Exp & Num & Exp & Num \\
\hline $\mathrm{H}=4$ & $0.62 \%$ & $0.65 \%$ & $0.67 \%$ & $0.68 \%$ & $0.75 \%$ & $0.77 \%$ & $0.75 \%$ & $0.77 \%$ & $0.76 \%$ & $0.80 \%$ \\
\hline $\mathrm{H}=6$ & $0.57 \%$ & $0.62 \%$ & $0.61 \%$ & - & $0.76 \%$ & - & $0.76 \%$ & $0.79 \%$ & $0.82 \%$ & - \\
\hline $\mathrm{H}=8$ & $0.61 \%$ & $0.62 \%$ & $0.63 \%$ & $0.66 \%$ & $0.80 \%$ & $0.77 \%$ & $0.83 \%$ & $0.86 \%$ & $0.85 \%$ & $0.86 \%$ \\
\hline
\end{tabular}

As can be seen from the graphs see Table 1 the influence of length of the wall, the efficiency increases with the length of the wall. Indeed, there is between 0 and $10 \mathrm{~cm}$ (short walls), efficiency remains almost constant or increases slightly (between 50 and 65\%) and that from 15 $\mathrm{cm}$ (or $15 \mathrm{~m}$ real) it increases visibly to reach efficiency going to 85\%. We can assume from these results that there is wall length (between $10 \mathrm{~m}$ and $15 \mathrm{~m}$ real) be necessary to surpass to get good results in terms of efficiency. Qualitatively, it can be seen in the last part of the film recorded from experiment and CFD motion by Smoke view that in the case of the influence of parameter without Wall extension $(\mathrm{L}=0 \mathrm{~m})$ a depression zone is visible near the front of exhausted tube. This inevitable area is a trap of smoke and recirculation flow. This phenomenon is very clear up to $m=2$. For the essay realized in $m=3$, it seems that most of the plume reaches around this zone. Nevertheless, there is still recirculation (short circuit flow). It appears very clearly that the offset tunnel portal entrance exit is more effective than the central dividing wall. An excellent efficiency registered with coherent offsetting head. In other hand, offsetting portal design required more concrete and extending tunnel by supplementary 
confined space. For this reason we focus to the simplest and economical design a central dividing wall. In general, the CFD model agrees reasonably with the experimental data and gives good convergence. A comparison of the short circuit percentages from experiment with the short circuit percentages from the simulation used central dividing wall shows that these can be reproduced in general with sufficient accuracy of $+/-(1 \sim 3 \%)$ exception under speed ratio of $\mathrm{m}=\mathrm{U}_{\mathrm{w}} / \mathrm{V}_{\mathrm{t}}=0.5$ see Table I case (a) a maximum accuracy occurring between $3 \sim 7 \%$.

\subsection{Physical Analysis and Optimization}

In order to better validate the data cited above (Table I) which is generally sufficient to provide answers at this stage to control pollutants in vicinity of tunnel portals and prevent air contamination of nearby tube. Except certain cases, such as the variation of the efficiency vs. height $\mathrm{H}$ of divided wall which may represent particularly significant issue and required more analysis. A sufficiently detailed study using analysis must be carried out in order to provide more detailed answers by CFD code in the same 1:100 scale of experiment to distinguish that there are two different manners in the variation of the efficiency vs. height $\mathrm{H}$ of divided wall as of wall length $\mathrm{L} \approx 10 \mathrm{~cm}(10 \mathrm{~m}$ real $)$ ?

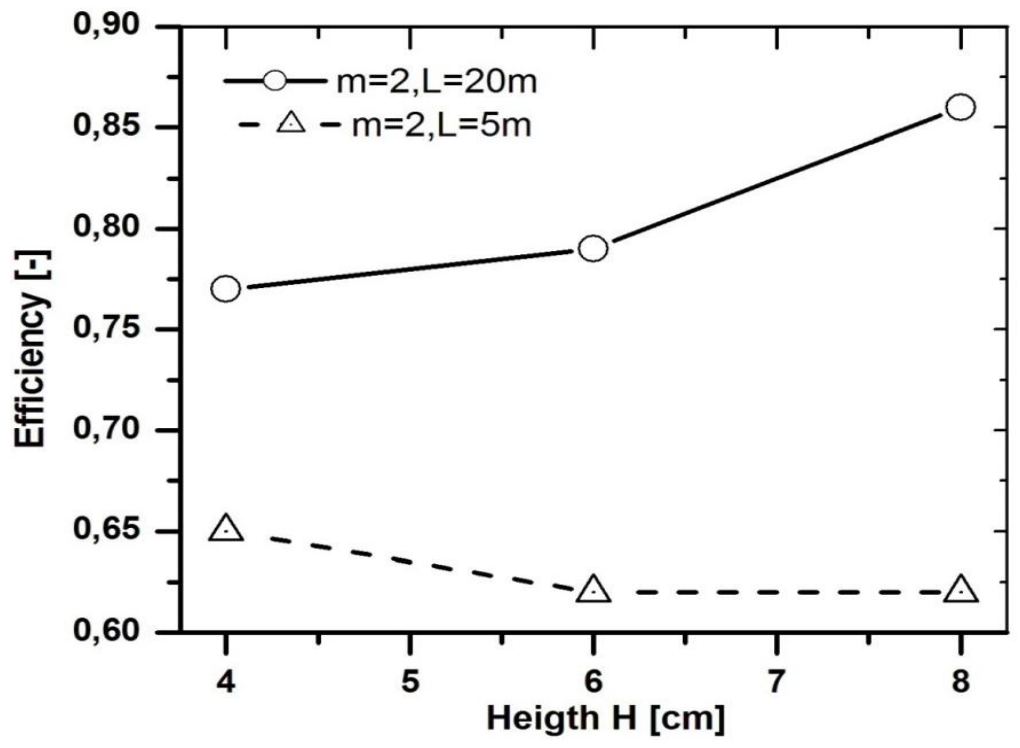

Fig. 5. Efficiency $\varepsilon$ versus the height of central dividing wall under fixed speed ratio $m=U_{w} / V_{t}=2$.

The efficiency increases with elevated wall sizes (See Fig. $5 \mathrm{~L}=20 \mathrm{~cm}$ ) which is quite logical. But, for de smaller length wall less than $10 \mathrm{~cm}(10 \mathrm{~m}$ real $)$ another approach becomes visible warranted by decrease of efficiency with elevate height, in this case it may be helpful to analysis the concentration and flow velocities near the wall. Initially we start to illustrate by a confidently $\mathrm{CO}_{2}$ concentration for walls of the largest length, which is logical because the great height prevents recirculation (Fig. 6).

The minimum values for $\mathrm{CO}_{2}$ concentration in the supply tube can be seen in the case of a tall wall (see Fig.6(a)) to mean more than $\mathrm{L} \approx 10 \mathrm{~cm}(10 \mathrm{~m})$ the recirculation decrease gradually while the wall increase toward the optimal length corresponding to no recirculation. A length of $15 \mathrm{~cm}$ (15 m real) is observed as best length of central dividing wall. 


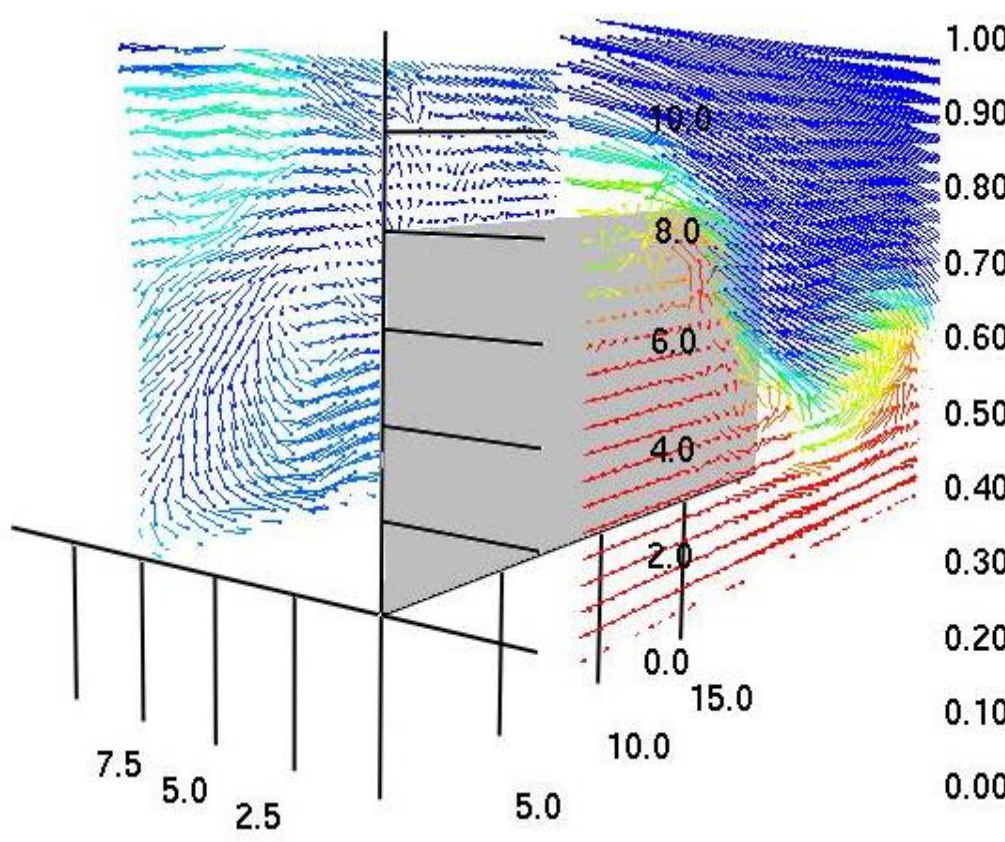

1.00

0.90

0.80

0.70

0.60

0.50

0.40

0.30

0.20

0.10

0.00

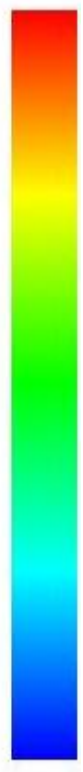

(a)

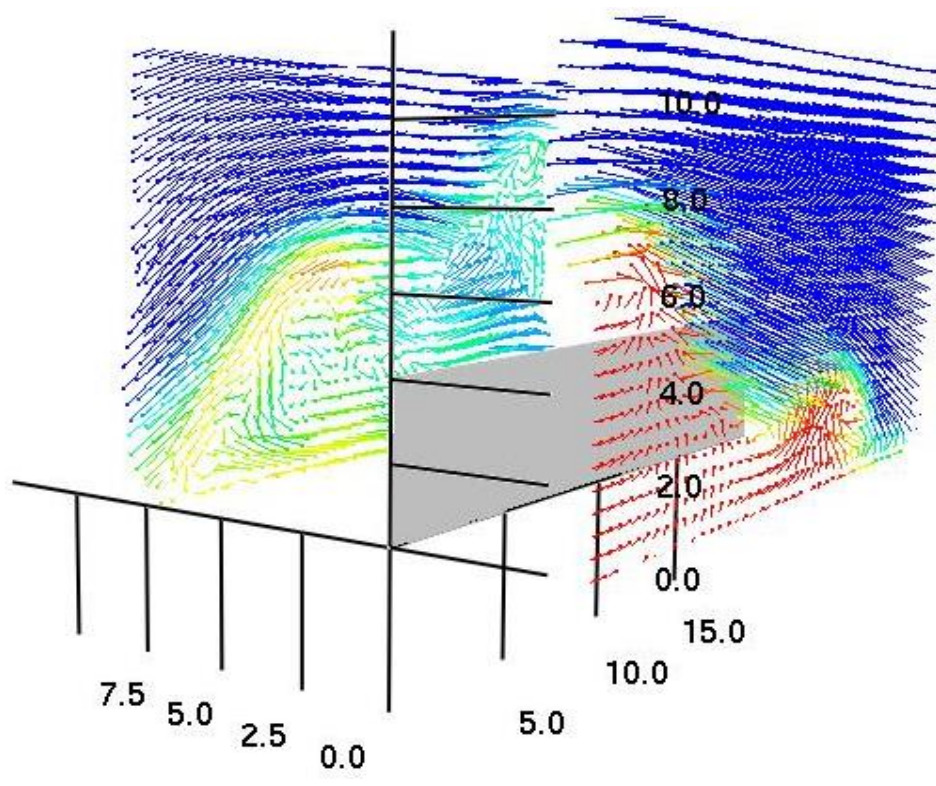

1.00

0.90

0.80

0.70

0.60

0.50

0.40

0.30

0.20

0.10

0.00

(b)

Fig. 6. The evaluation of $\mathrm{CO}_{2}$ concentration levels (Kg.Kg-1) with flow direction for the different sizes of central dividing wall: (a) wall $(\mathrm{H}=08 \mathrm{~cm}, \mathrm{~L}=20 \mathrm{~cm})$ and (b) wall $(\mathrm{H}=04 \mathrm{~cm}, \mathrm{~L}=20 \mathrm{~cm})$.

In the case of the short wall $(\mathrm{H}=04 \mathrm{~cm}, \mathrm{~L}=05 \mathrm{~cm})$ near the supply tube a turbulent vortex imprison the flow in their area and prevent $\mathrm{CO}_{2}$ gas to directed toward the supply tube. However, without a vortex for $(\mathrm{H}=08 \mathrm{~cm}, \mathrm{~L}=05 \mathrm{~cm})$ the ventilated supply tube aspirated quietly a $\mathrm{CO}_{2}$ gas. So, the task is to determine which cause that encourage the formation of a vortex for the case of small height $(\mathrm{H}=04 \mathrm{~cm}, \mathrm{~L}=05 \mathrm{~cm}$ ) (see Fig.7). 

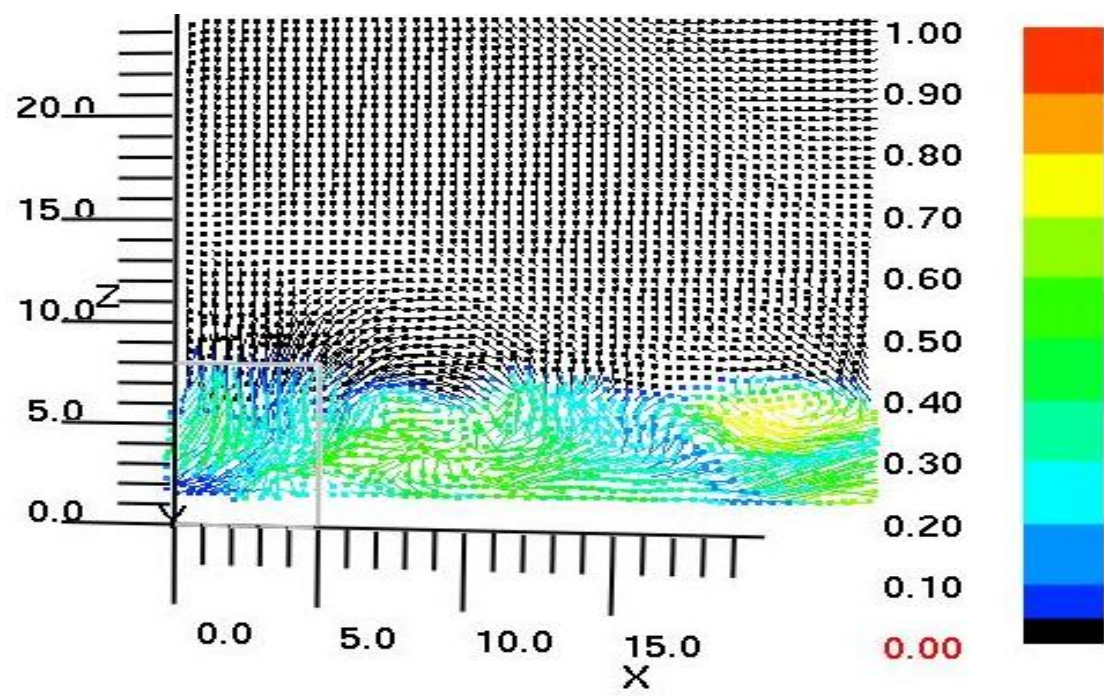

(a)
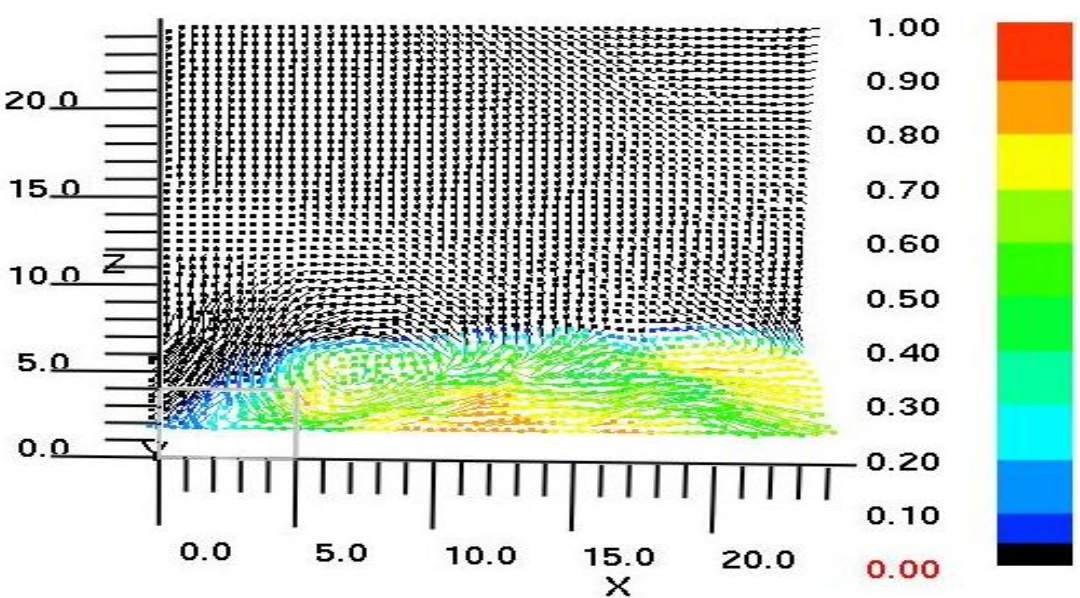

(b)
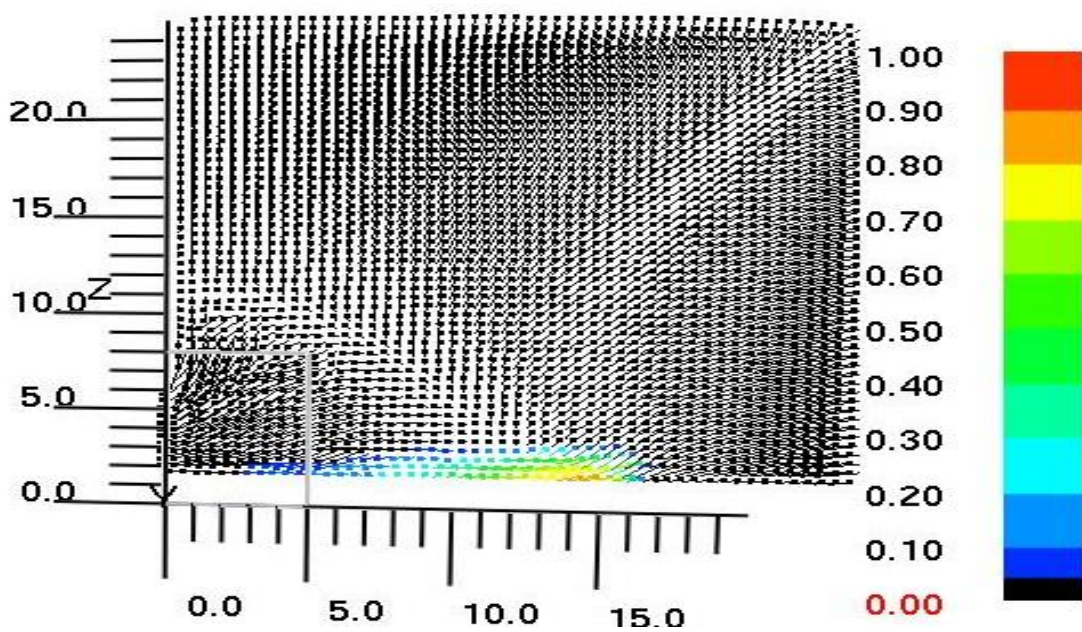

(c)

Fig. 7. $\mathrm{CO}_{2}$ concentration $(\mathrm{Kg}$. $\mathrm{Kg}-1)$ in the supply tube (plane $\left.\mathrm{Y}=7.5\right):(\mathrm{a})$ wall $(\mathrm{H}=08 \mathrm{~cm}, \mathrm{~L}=05 \mathrm{~cm})$, (b) wall $(\mathrm{H}=04 \mathrm{~cm}, \mathrm{~L}=05 \mathrm{~cm})$ and $(\mathrm{c})$ Temporal appearance of $\mathrm{CO}_{2}(\mathrm{Kg} . \mathrm{Kg}-1)$ for a used wall $(\mathrm{H}=08 \mathrm{~cm}, \mathrm{~L}=05 \mathrm{~cm})$ at time $\mathrm{t}=5.6 \mathrm{~S}$. 
The smaller divided wall playing considerable effect during the vortex creation justified by less blocking effect of the adverse wind as well as favorite more the interaction with longitudinal flow of supply tube. The interaction decrease with elevated height of central dividing wall which can block the short circuit flow in the region near portals and to let mixture near ground of supply tube affected only by longitudinal ventilation imposed by the fan, in addition the cross $\mathrm{CO}_{2}$ flow decrease front supply tube with increasing wall length up to a limit of $\mathrm{L}=15 \mathrm{~cm}$ that the supply tube can aspirate only fresh air. Furthermore, from animated results of CFD postprocessing, the first appearance of $\mathrm{CO}_{2}$ with high concentration in the longitudinal plane of the supply tube is approximately $15 \mathrm{~cm}$ in all cases of smaller divided wall we have presented only $(\mathrm{H}=08 \mathrm{~cm}, \mathrm{~L}=05 \mathrm{~cm})$ in Fig. 7.c. From this distance equal to $15 \mathrm{~cm}(15 \mathrm{~m})$ the main propagation of $\mathrm{CO}_{2}$ from exhaust tube under longitudinal ventilation can be affected by transversal wind easily and the main flow move transversely. After that the $\mathrm{CO}_{2}$ collect, diffuse in the fresh air area and obey to speed rate condition of supply tube, they interact gradually in their way to the upward/downward flow of wind crossed the head of a dividing wall.

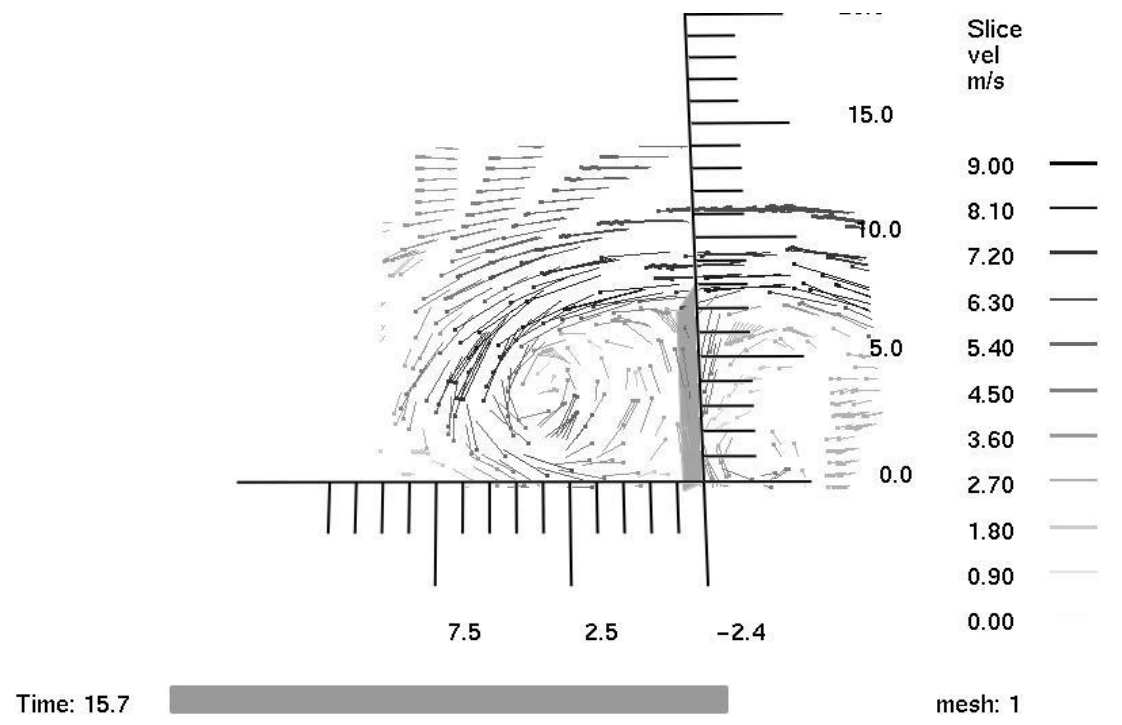

Fig. 8. Flow velocity in the plane $X=5 \mathrm{~cm}$ toward supply tube formed a vortex observed in upstream side of the wall.

A cross analysis near the portal in the coordinate plane $\mathrm{x}=5 \mathrm{~cm}$ chosen to more identify the blocking of turbulence vortex. A vortex observed in upstream side of the wall $\mathrm{H}=08 \mathrm{~cm}$ which be a sign of the divided cross flow through top of a central dividing wall: one part of the crossflow directed downwardly in upstream the wall and creates a vortex and other flow goes across the wall upwardly (see Fig.8). For $\mathrm{H}=08 \mathrm{~cm}$ subdivisions of the cross flow and creation of the vortex upstream moreover downstream the wall which hinder the upward flow at high-speed, the vortex in this area encourage more recirculation. for $\mathrm{H}=04$ without any vortex produced and upward cross flow with high-speed decreased recirculation and appearance of a stagnation zone in the portal of supply tube $\mathrm{H}=04 \mathrm{~cm}$, the area downstream of the wall with the lower speed and the maximum concentration, but remains blocked such as the supply tube acquire flow from the descending flow.

\section{Conclusions}

From present results of the numerical and experiment studies, the following conclusion can be assumed: Large-eddy simulation (LES) model can correctly predict pollutant dispersion in the vicinity of road tunnel. A description of the critical pollutants' recirculation rate as a function of the wind speed and wall sizes of central dividing wall has been presented. It uses concentration of contaminant as a safety criterion. Computational Fluid Dynamics (CFD) models validated, for the simulation of the behavior of contaminant originating from short-circuiting flow between 
tube of road tunnel for both structure of tunnel portal designs such as "Central Dividing Wall" and "Offset Tunnel Portal Entrance Exit" designs. The comparison of this result to the available experimental recirculation data between tunnel portals shows that pollutants recirculation will be sensitive to height of central dividing Wall and wind conditions. The recirculation corresponded to offset tunnel portal entrance exit can be expected to be generally less critical due to the less mixing of the pollutants discharge under wind orientation to the ambient air aspirated by offsetting tube. From present results of the numerical and experiment studies, the following conclusion can be assumed: Large-eddy simulation (LES) model can correctly predict pollutant dispersion in the vicinity of road tunnel. A description of the critical pollutants' recirculation rate as a function of the wind speed and wall sizes of central dividing wall has been presented. It uses concentration of contaminant as a safety criterion. Computational Fluid Dynamics (CFD) models validated, for the simulation of the behavior of contaminant originating from short-circuiting flow between tube of road tunnel for both structures of tunnel portals tested such as a "Central Dividing Wall" and "Offset Tunnel Portal Entrance Exit" designs. The comparison the CFD data to the available experimental data based to the predicted amount of pollutant air short circuit between tunnel portals shows that this amount is sensitive to height of Central dividing Wall and wind conditions. This study illustrated the use of CFD to increase insight in building aerodynamics and to support sustainable tunnel design. Therefore, information about wind flow patterns around tunnel portals can be important to the designers, should pay more attention in creating more safety tunnel. The results should serve as groundwork for the design of ventilation systems to be as well as for the refurbishment of existing systems.

\section{Perspective}

Computational Fluid Dynamics (CFD) models will be used to validate for the simulation of the behavior of smoke originating from fires in the two tunnels. Nevertheless, the evaluation of smoke recirculation should more detail in the event of a fire recirculation, it must take into account the models limitations and the transients of a tunnel fire, i.e. the fire growth, the switch from the normal to emergency ventilation.

\section{Acknowledgments}

This work was supported by the Algerian Research Organism "DGRSDT Directorate General for Scientific Research and Technological Development" under the project [No.A11N01UN020120150001]. Pro acknowledged for Pr.Olivier Vauquelin for his kind help and discussions during the preparation of the present article. The author would also like to thank the Institute Universitaire des Systèmes Thermiques Industriels, IUSTI UMR CNRS 7343 Technopôle de château-Gombert. UNIVERSITÉ D’AIX-MARSEILLE, Marseille cedex13, France for their collaboration.

\section{References}

Baumann, H.O., (1979). Air Recirculation between Tunnel Portals. 3rd Int. Symposium on the Aerodynamics and Ventilation of Vehicle Tunnels, Sheffield.

Brousse, B., Vidal, B., Ponticq, X., Goupil, G., \& Alary, R. (2005). Pollution dispersion at an urban motorway tunnel portal: Comparison of the small-scale predictive study with the actual conditions measured on the site. Atmospheric Environment, 39(13), 2459-2473.

Chock, D. P. (1982). Pollutant dispersion near roadways-experiments and modeling. Science of the Total Environment, 25(2), 111-132.

Dagnew, A. K., \& Bitsuamlak, G. T. (2014). Computational evaluation of wind loads on a standard tall building using LES. Wind and Structures, 18(5), 567-598.

Dagnew, A., \& Bitsuamlak, G. T. (2013). Computational evaluation of wind loads on buildings: a review. Wind Struct, 16(6), 629-660. 
Davidson, L., \& Nielsen, P, (1996). Large eddy simulation of the flow in a three-dimensional ventilation room. $5^{\text {th }}$ International Conference on Air Distribution in Rooms, ROOMVENT96, July 17-19.

Gehrig, S., Buchmann, R., \& Yousaf, R. (2013). How much flow recirculation is acceptable at tunnel portals?. World Tunnel Congress, Geneva Underground - the way to the future! G. Anagnostou \& H. Ehrbar. Eds Taylor \& Francis Group, London.

Gourdol, F., (2004). Study on a mock-up of a dispersion scenario at tunnel portal-test report. CETU Guide, Environmental studies in road projects "Air" and "Health" sections the specific case of tunnels. École Central de Lyon France. http://www.cetu.developpement-durable.gouv.fr

Kashef, A., Lougheed, G. D., \& Benichou, N. (2003). Numerical Modelling of Movement and Behaviour of Smoke Produced from Fires in the Ville-Marie and LH-La Fontaine Tunnel: Literature Review. Ottawa: Institute for Research in Construction, National Research Council Canada.

Koopmans, J. F. W. (2005). Air pollution short circuit effects of road traffic tunnel portal. In Symposium Air Quality Management Vol. 7, Istanbul.

Li, S. W., Hu, Z. Z., Tse, K. T., \& Weerasuriya, A. U. (2016). Wind direction field under the influence of topography: part II: CFD investigations. Wind Struct, 22(4), 477-501.

Lim, H. C., \& Ohba, M. (2015). Detached eddy simulation of flow around rectangular bodies with different aspect ratios. Wind and Structures, 20(1), 37-58.

Lipecki, T., \& Flaga, A. (2013). Vortex excitation model. Part I. mathematical description and numerical implementation. Wind and Structures, 16(5), 457-476.

McGrattan, K., Hostikka, S., McDermott, R., Floyd, J., Weinschenk, C., \& Overholt, K. (2013). Fire dynamics simulator user's guide. NIST special publication, 1019(6).

Mirzai, M. H., Harvey, J. K., \& Jones, C. D. (1994). Wind tunnel investigation of dispersion of pollutants due to wind flow around a small building. Atmospheric Environment, 28(11), 1819-1826.

Muhic, S., \& Mazej, M. (2014). Computational study of road tunnel exposure to severe wind conditions. Wind and Structures, 19(2), 185-197.

Murakami, S. (1998). Overview of turbulence models applied in CWE-1997. Journal of Wind Engineering and Industrial Aerodynamics, 74, 1-24.

Musser, A., McGrattan, K. B., \& Palmer, J. M. (2001). Evaluation of a fast, simplified computational fluid dynamics model for solving room airflow problems (No. NIST Interagency/Internal Report (NISTIR)-6760).

Nadel, C., Thompson, K.A., Slusarczyk, J.L. \& Vanderheyden, M.D. (2003). Use of wind tunnel testing to develop air rights structures over tunnel exit portals that are compliant with ambient air quality standards. Proceedings of the $11^{\text {th }}$ International Symposium on Aerodynamics and Ventilation of Vehicle Tunnels, Luzern, Switzerland.

Oettl, D., Sturm, P., Almbauer, R., Okamoto, S. I., \& Horiuchi, K. (2003). Dispersion from road tunnel portals: comparison of two different modelling approaches. Atmospheric Environment, 37(37), 51655175.

Peila, D., \& Pelizza, S. (2002). Criteria for technical and environmental design of tunnel portals. Tunnelling and underground space technology, 17(4), 335-340.

Rehm, R. G., \& Baum, H. R. (1978). The equations of motion for thermally driven, buoyant flows. Journal of Research of the NBS, 83(3), 297-308.

Smagorinsky, J. (1963) General Circulation Experiments with the primitive equations I, The basic experiment. Monthly Weather review: 91-99.

Tan, X., Chen, W., Dai, Y., Wu, G., Yang, J., Jia, S., ... \& Li, F. (2015). Experimental research on the mixture mechanism of polluted and fresh air at the portal of small-space road tunnels. Tunnelling and Underground Space Technology, 50, 118-128.

Tanaka, F., Kawabata, N., \& Ura, F. (2016). Effects of a transverse external wind on natural ventilation during fires in shallow urban road tunnels with roof openings. Fire Safety Journal, 79, 20-36. 
Vauquelin, O. \& Lesueur, H., 1998. Etude expérimentale sur maquette du recyclage de l'air vicié en tête d'un tunnel bitude. Université de Valenciennes, report for Scetauroute DTTS. 'Unpublished results'

Weerasuriya, A. U., Hu, Z. Z., Li, S. W., \& Tse, K. T. (2016). Wind direction field under the influence of topography, part I: A descriptive model. Wind Struct, 22(4), 455-476.

Yang, Y. R., He, C., Zeng, Y. H., \& Fang, Y. (2012). Effect of structural factors on waste gas cross flowing around portal of highway tunnels. Zhongguo Gonglu Xuebao(China Journal of Highway and Transport), 25(4), 107-112.

Yousaf, R., Gehrig, S., \& Buchmann, R. (2014). Evaluating smoke recirculation potential at the portal of a swiss road tunnel in case of a fire. In 7 th international conference on tunnel safety and ventilation. pp. 118-125.

\section{Nomenclature}

$C_{P} \quad$ Specific heat capacity of the gas

$C_{\mathrm{s}} \quad$ Smagorinsky constant

$C_{\mu}, C_{\varepsilon} \quad$ empirical constants in turbulence model

$\delta_{X}, \delta_{Y}, \delta_{Z}$ the dimensions of the smallest me $g_{i}$ acceleration of gravity (x,y and Z)

$h \quad$ enthalpy

$H \quad$ height of tunnel exit

$\mathrm{k} \quad$ turbulent kinetic energy

$K_{S} \quad$ thermal conductivity of tunnel portal and ground wall.

$P \quad$ pressure

$P_{0} \quad$ ambient pressure

$\mathrm{Pr}_{t} \quad$ turbulent Prandtl number

.

$q_{r} \quad$ radiative flux to a solid surface.

."

$q_{c} \quad$ convective flux to a solid surface.

$R \quad$ universal gas constant

$S_{i j} \quad$ local large-scale rate of strain

$S c_{\mathrm{t}} \quad$ turbulent Schmidt number

$t \quad$ time

$T \quad$ temperature

$T_{0} \quad$ ambient temperature

$U=(u, v, w)$ velocity vector

$U_{0} \quad$ initial velocity

\section{Greek symbol}

$\varepsilon \quad$ dissipation of the turbulent kinetic energy 


$\begin{array}{ll}u & \text { dynamic viscosity } \\ u_{t} & \text { subgrid-scale turbulent viscosity } \\ \rho & \text { air density } \\ \text { Overbar } & \\ \bar{\wp} & \text { filtered variable } \\ \rho_{0} & \text { ambient air density } \\ \sigma & \text { Stefan-Boltzmann constant } \\ \tau_{i j, \mathrm{SGS}} & \text { subgrid-scale Reynolds stress tensor } \\ \Delta & \text { filter width } \\ \Phi(\vec{x}, t) & \text { general variable } \\ \bar{\Phi}(\vec{x}, t) & \text { large-scale component } \\ \Phi^{\prime}(\vec{x}, t) & \text { subgrid-scale component }\end{array}$

